\title{
Confesiones subalternas: subjetivación, relato y culpa en tres novelas argentinas y chilenas de la posdictadura ${ }^{1}$
}

\section{Subaltern confessions: subjectification, narrative and guilt in three Argentine and Chilean post-dictatorship novels}

\author{
Macarena Areco \\ Universidad Diego Portales, Chile \\ mareco@uc.cl
}

\section{Resumen}

En este trabajo intento elaborar una reflexión acerca del régimen de repartición de culpas y de exención de responsabilidad en la posdictadura, a partir de la pregunta acerca de quiénes son los sujetos que se confiesan en algunas obras narrativas recientes. Para ello analizo tres novelas argentinas y chilenas -Ciencias morales (2007) de Martín Kohan, La vida doble (2010) de Arturo Fontaine y Carne de perra (2009) de Fátima Sime- protagonizadas por mujeres, que, de manera más o menos obligada o más o menos voluntaria, asumieron labores represivas e incluso criminales, en los setenta y ochenta en sus países.

Palabras clave: confesión, dictadura, posdictadura, novelas argentinas y chilenas recientes.

\section{Abstract}

In this paper I try to elaborate a reflection about the regime of distribution of guilt and of exemption of responsibility in the post-dictatorship period, wwfrom the question about the subjects that confess in recent narrative works. To do this, I analyze three Argentine and Chilean novels -Ciencias morales (2007) by Martin Kohan, La vida doble (2010) by Arturo Fontaine and Carne de perra (2009) by Fátima Sime- all of which leading parts are women who, in a more or less compelled or voluntary way, took up repressive and even criminal roles, in the seventies and eighties in their countries.

Keywords: Confession, Dictatorship, Post-dictatorship, recent Argentine and Chilean novels.

1 Este artículo fue escrito en el marco del proyecto Fondecyt Regular $\mathrm{N}^{\circ} 1130489$ y fue leído en una versión inicial en la Jornada Internacional "La confesión en la literatura latinoamericana", organizada por el CRLA de la Universidad de Poitiers y el GRELP de la Universidad de París Ouest Nanterre y realizada en diciembre de 2013. 
Cuál mayor culpa ha tenido en una pasión errada:

la que cae de rogada, o el que ruega de caído?

¿O cuál es más de culpar, aunque cualquiera mal haga:

la peca por la paga, o el que paga por pecar?

Suplico por amor a Dios y de su Purísima Madre, a mis amadas hermanas religiosas que son y en lo adelante fuesen, me encomienden a Dios, que he sido y soy la peor que ha habido. A todas pido perdón por amor a Dios y de su madre. Yo, la peor del mundo Sor Juana Inés de la Cruz, "Sátira filosófica" y Libro de profesiones del convento

Mientras en el ámbito judicial y mediático los principales responsables de las violaciones a los derechos humanos en la dictadura chilena han mantenido silencio respecto al reconocimiento de sus crímenes ${ }^{2}$, en los últimos años, en la escritura que aborda ese periodo, empiezan a aparecer confesiones detalladas de personas involucradas en el terrorismo de estado. Si examinamos quiénes son los sujetos de estas confesiones, constatamos que en su mayoría son personajes subalternos, especialmente mujeres, que participaron muchas veces obligadas en la represión. En este trabajo me propongo abordar la presencia de la confesión en algunas narraciones argentinas y chilenas recientes a partir del análisis de tres novelas -la argentina Ciencias morales (2007) de Martín Kohan y las chilenas La vida doble (2010) de Arturo Fontaine y Carne de perra (2009) de Fátima Sime- cuyas protagonistas son mujeres, que, de manera más o menos alienada o más o menos voluntaria asumieron labores represivas e incluso en las dos últimas, criminales, en los setenta y ochenta en sus países.

En el caso chileno, en los años noventa las primeras en testimoniar por escrito sobre sus culpas fueron las ex militantes ultra izquierdistas que se pasaron al bando

2 Este es el caso de Manuel Contreras, director de la Dirección Nacional de Inteligencia (DINA) entre 1973 y 1977 y máximo responsable de los secuestros, torturas y asesinatos de esos años, quien, por ejemplo en la carta pública de 2005 "Introducción a la entrega de documentos que demuestran las verdaderas responsabilidades de las instituciones de la defensa nacional en la lucha contra el terrorismo en Chile", justifica sus acciones. He tenido conocimiento de este documento gracias al esclarecedor artículo de Domingo Román "Personas e individuos. Crítica de un documento del General (r) Contreras". http://www.domingo-roman.net/Documentos/Personas_e_individuos_Carta.pdf 
enemigo Luz Arce en El infierno (1993) y Marcia Merino en Mi verdad: más allá del horror, yo acuso... (1993). Un caso de un hombre que podríamos poner en esta serie es el de Miguel Krassnoff, pero no es difícil darse cuenta de que la comparación es imposible, no sólo porque el protagonista de Prisionero por servir a Chile ${ }^{3}$ fue parte del estamento superior del Ejército y de la institucionalidad represiva mientras que Arce y Merino colaboraron después de ser secuestradas y torturadas, sino además porque nada de contrición hay en sus palabras. Se puede leer, por ejemplo, en un blog sobre este personaje la siguiente afirmación:

Pese a las acusaciones, mantengo en alto mi ánimo y mi inquebrantable fe en Dios. Que todos sepan que soy un cosaco y me siento orgulloso de ello, mismo sentimiento que guardo por usar el uniforme de Oficial [sic] del Ejército de Chile. Soy un Soldado [sic] al que han transformado en un perseguido político, pero no en un militar chileno derrotado, ni mucho menos en un cosaco postrado (miguelkrassnoff.blogspot.com)

En la misma página se dice que Krassnoff es "un real prisionero político, por el solo hecho de Servir [sic] a Chile" y que "No hay ninguna prueba legal que confirme di-

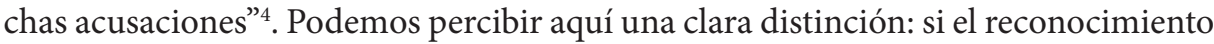
del infierno y el horror es el punto de partida de los testimonios de las mujeres, el de Krassnoff es un heroico servicio a la Patria, sin mácula ${ }^{5}$.

\section{Confesión y poder}

Como ha escrito Michel Foucault, la conminación a confesarse es una acción que está involucrada en una estructura jerárquica de dominación: "la confesión... es un ritual que se despliega en una relación de poder, pues no se confiesa sin la presencia al menos virtual de otro que no es simplemente el interlocutor sino la instancia que requiere la confesión, la impone, la aprecia e interviene para juzgar, castigar, perdonar, consolar, reconciliar" (Historia de la sexualidad 77). Según el investigador, es ésta una "palabra obligada, requerida, que por una coerción imperiosa hace saltar los sellos de la discreción y del olvido", en la cual "la instancia de dominación no está del lado del que habla (pues es él el coercionado) sino del que escucha y se calla; no del lado del que sabe y formula una respuesta, sino del que interroga y no pasa por saber" (79).

3 Escrito por Gisela Silva Encina y publicado en 2007.

4 http://miguelkrassnoff.blogspot.com/. En Confesiones de un torturador, entrevista realizada por Nancy Guzmán al integrante de la DINA Osvaldo Romo, tampoco aparece, a pesar del título, el arrepentimiento.

5 Un texto que presenta un posicionamiento intermedio entre el horror y el heroísmo es el libro de memorias Siembra vientos (1995) de Mariana Callejas -escritora y agente de la DINA que participó, entre otros, en el asesinato del canciller de Allende Orlando Letelier en Nueva York-, muy ambiguo respecto a asumir responsabilidades, que no es ni una confesión ni una defensa de lo realizado. 
Foucault escribe lo anterior en el primer tomo de la Historia de la sexualidad como parte de su argumentación respecto a que la creciente apelación a hablar sobre el sexo, primero en el marco del cristianismo y luego del psicoanálisis, no es una liberación sino una técnica de subjetivación destinada a producir cuerpos dóciles. Inspirándome en el pensador francés, propongo que la confesión, de manera contraria al discurso cristiano que nos enseña que la verdad, y en especial la verdad sobre nosotros mismos, nos hace libres, es un estrategia destinada al control subjetivo, en la cual un subordinado, que ocupa la posición de pecador o penitente, entrega a un superior información para él relevante que permite al otro dominarlo. Recordemos aquí las palabras de la monja santiaguina Úrsula Suárez (1666-1749), quien en el inicio de su Relación autobiográfica ${ }^{6}$, temiendo los problemas que podría generarle la autobiografía escrita que su confesor le exige, se atiene a "la divina voluntad ordenada por la de vuestra paternidad", pero no lo hace de buen grado: "con lágrimas referiré toda mi vida pasada, que anegada en el mar de mis lágrimas no sé cómo principiar" (90).

¿Cuál es el objetivo de la confesión? Construir cuerpos dóciles, sí, por supuesto, pero al mismo tiempo producir una administración de la culpa. Se inviste a algunos con los mayores pesos morales con su propia ayuda, se libera a otros, se los deja de lado. Entonces, el que sean las mujeres las que muchas veces se confiesan en la narrativa del 2000 en relación con los crímenes dictatoriales indica, me parece, un modo de distribuir, tal vez inicialmente (no sabemos qué se seguirá escribiendo después), el peso, de disponer de sujetos a quienes cargar y de poder así eximir a otros, menos precarios, más empoderados (los jefes, los torturadores), como un modo de liberarlos de responsabilidad. Quien se confiesa en las novelas recientes revela una parte del mapa administrativo-político de las culpas en el imaginario de la posdictadura. También el cómo lo hace algo nos muestra.

\section{La preceptora purista}

En la novela de Martín Kohan Ciencias morales (Premio Herralde 2007), la protagonista es María Teresa, la joven preceptora de un liceo emblemático bonaerense, el Colegio Nacional, quien, a comienzos de los ochenta, está obsesionada, primero, por la distancia que mantienen los estudiantes en la fila en la formación inicial de la mañana y, más adelante, por la sospecha de que algunos jóvenes fuman en el baño. Para descubrir a los infractores se encierra en el servicio de hombres, al inicio por un tiempo breve, más adelante durante horas, sin que su pesquisa resulte exitosa. En cambio, es descubierta por el jefe de preceptores, el señor Biasutto, quien se aprovecha de la situación y la viola en el baño.

6 La obra data de principios del siglo XVIII y pasó prácticamente inadvertida. Es reseñada por primera vez en 1850 (Historia Eclesiástica, Política y Literaria de Chile de José Ignacio Víctor Eyzaguirre). Recién a fines del siglo XX es valorada en el marco de las historias de la vida privada y de las mujeres en la Colonia. 
Con una narración en tercera persona que esconde una focalización extremadamente cerrada en María Teresa, el relato entrega escasos datos, siempre indiciales, sobre el contexto político de la historia: el control excesivo sobre los estudiantes, el desconocimiento de lo que ocurre con el hermano conscripto que, suponemos, ha sido o será enviado a Las Malvinas, alguna manifestación callejera en el centro y sobre todo, la información que, filtrada por la visión de la protagonista, se entrega de Biasutto, quien, se dice, "cuenta con gran prestigio en el colegio porque es sabido que, hace unos años, fue el responsable principal de la confección de listas, y se dará por seguro que en algún momento, cuando la dinámica de la designación de autoridades lo permita, ocupará a su vez el cargo de Prefecto" (25). Nótese que se habla del prestigio de un delator y que en ello no hay ninguna ironía desde la voz narrativa ubicada en la conciencia de la protagonista. Algo distinto es lo que ocurre con lo que podríamos llamar la ley de valores de la novela, que en este caso se expresa a través de la trama en la violación hacia el final del relato, que da cuenta de lo equivocada que estaba María Teresa.

La obra de Kohan no es propiamente una confesión. Si la analizo, sin embargo, es porque me parece que sienta algunas bases que ayudan a pensar en este tipo de discurso en el sentido en que me interesa. Ellas son el que sea una mujer la protagonista, y no por ejemplo Biasutto, quien, uno consideraría, tiene mayores motivos para confesarse; el empleo de la tercera persona, que analizaré con algún detalle a continuación; y la posibilidad de leerla como una historia que, al modo del mito, intenta responder una pregunta sobre los orígenes, en este caso de la colaboración de personas comunes y corrientes con el terrorismo de estado o, visto desde el otro lado, sobre lo que Hannah Arendt llamó, a propósito del juicio a Eichmann en Jerusalén, la banalidad del mal ${ }^{7}$. En particular, me parece que la propuesta de Kohan, tiene que ver con el modo narrativo elegido para contar esta historia, una tercera persona que inicialmente engaña con una aparente apertura, pero que, ya desde el comienzo, se cierra de manera que lo que aparece son, no ya las rejas del lenguaje a las que se refería Celan, que impiden la comunicación de la experiencia, sino que los muros de la conciencia enclaustrada e identificada con la ideología, incapaz de ver más allá. Creo que el inicio de la novela es muy significativo para esta interpretación, por lo que lo cito en extenso:

Alguna vez este colegio, el Colegio Nacional, fue solamente de varones. En esos tiempos ya distantes, los tiempos del Colegio de Ciencias Morales, por no decir los más remotos del Real Colegio de San Carlos, las cosas debieron ser, por necesidad, más claras y ordenadas. Es simple: faltaba ni más ni menos que la mitad de este mundo que ahora lo integra. Esa mitad hecha de jumpers, de vinchas, esa mitad hecha de cintas y de hebillas, esa mitad que requirió de la instalación de baños aparte

7 "Lo más grave, en el caso de Eichmann, era precisamente que hubo muchos hombres como él, y que estos hombres no fueron pervertidos ni sádicos, sino que fueron, y siguen siendo, terrible y terroríficamente normales. Desde el punto de vista de nuestras instituciones jurídicas y de nuestros criterios morales, esta normalidad resultaba mucho más terrorífica que todas las atrocidades juntas, por cuanto implicaba que este nuevo tipo de delincuente (...) comete sus fechorías en circunstancias que casi le impiden saber o intuir que realiza actos de maldad" (Arendt 417). 
en el colegio... antes, mucho antes, en los tiempos de Miguel Cané, en los tiempos de Amadeo Jacques, sencillamente no existía. El colegio era todo una misma cosa, era todo de varones. Entonces con toda seguridad las actividades transcurrían de manera más sosegada, o por lo menos eso presume ahora, en el estado de distracción que la gana hacia el final del segundo recreo de la tarde, la preceptora de tercero décimo... Eso piensa, abstraída, aunque vigilante en la apariencia, María Teresa...

Se perciben varias cuestiones en este íncipit que nos pueden ayudar a alumbrar la pregunta por la colaboración en la violencia de estado. La apertura mítica con las repetidas alusiones al illo tempore, una edad de oro de perfección, que configura al presente, por contraste, como algo defectuoso, caracterizado por el desorden y el desasosiego, lo que prefigura la posibilidad de la acción para su mejoramiento. El tipo de perfección al que se alude, que da cuenta de un autoritarismo implícito: lo que se desea es una pureza del tipo único, que, además, se relaciona veladamente no con las relaciones de poder más explícitas, las oposiciones políticas o de clase, sino con las de género. Así, el mundo ideal con el que se fantasea es un espacio de hombres solos ordenados, sin cintitas ni hebillas, sin la desorganización que trae consigo esa otra mitad del mundo que son las mujeres, a las que ni siquiera se nombra y a las que sería mejor poder seguir dejando fuera de la historia y del texto. El personaje añora esas exclusiones, a pesar de que sabe que en ese orden ella no tendría espacio. Por otra parte, la narración en tercera persona, inicialmente presentada como omnisciente, muy pronto, con el giro un tanto forzado del "presume ahora", revela su foco: la mente de la preceptora María Teresa, quien, distraída y abstraída, piensa en aquellos tiempos pasados como mejores. Hay un paso casi imperceptible desde el mito a la mente, desde lo abierto a lo focalizado, desde la Historia al momento actual, que da cuenta, creo, de la naturalización que la ideología opera en el pensamiento, convirtiendo en verdad originaria y deseable lo que, como mucho, es un antecedente histórico, normalmente resultado de una desigualdad producida por las relaciones de poder. La ideología como una suerte de voz interior que nos habla en tercera persona, en la intimidad ensoñada de la mente, y que nos lleva a imaginar que se trata de nuestras propias ideas y deseos, incluso contra nuestros intereses. Recordemos para estos efectos la definición de Althusser: "La ideología es una representación de la relación imaginaria de los individuos con sus condiciones reales de existencia" (43). Si consideramos, además, que Barthes en Mitologías piensa a la ideología como mito burgués, el círculo se cierra: la narración mítica del tiempo perfecto de los orígenes del colegio coincide con la ideología autoritaria del orden y la univocidad como obligaciones para el sujeto en el presente. De ahí su carácter incuestionable al mismo tiempo que imperativo para María Teresa. En correspondencia con lo anterior, la narración continúa con una referencia a la vigilancia como la actitud del personaje, la cual va a ser el leit motiv de la obra ${ }^{8}$.

8 La vigilancia es también un leit motiv de obras anteriores que aluden a la dictadura. Por ejemplo la novela Los 
Así, la historia mítica del colegio y los pensamientos de María Teresa se funden y se produce la asimilación de los principios de orden y univocidad con los deseos personales, lo que conlleva a la obsesión por su cumplimiento, como se observa en la siguiente reflexión, relativa a la importancia esencial de la recta disposición de los estudiantes en la fila:

Tomar distancia es un aspecto fundamental en la formación de los alumnos del colegio. Hasta que toman distancia los alumnos lucen todavía en desorden, reunidos pero no formados, con cierto aire de dejadez que es indispensable despejar. Una vez que toman distancia la doble hilera adquiere en cambio rectitud y proporción, una justa simetría por lo demás muy adecuada (12).

En su búsqueda de la perfección del orden, la preceptora se focaliza en aquella zona difícil de la fila donde los géneros se reúnen y pueden producirse contactos indebidos: La otra tarde, al cabo del primer recreo, María Teresa notó o creyó notar, que la mano derecha de Capelán reposaba excesivamente en el hombro derecho de Marré. Tomaba distancia, sí, era su obligación y la acataba, pero quizás no solamente tomaba distancia. Una cosa era valerse de ese hombro como referencia para tomar distancia, y otra cosa muy distinta era sujetar ese hombro, tocarlo, envolverlo en la mano...

-¿Está cansado, Capelán?

-No, señorita preceptora.

- ¿Le pesa el brazo, Capelán?

-No, señorita preceptora.

- ¿Tal vez prefiera salir de la formación, Capelán, y tomarse un descanso en el despacho del Prefecto?

-No, señorita preceptora.

Entonces tome distancia como se debe.

-Sí, señorita preceptora (14).

Percibimos a través de este afilado diálogo cómo María Teresa se hace dueña del poder y lo utiliza, y cómo el deseo de orden y la compulsión por cumplirlo se resuelve en autoritarismo. Lo que seguirá a continuación serán sus incursiones en el baño de varones para vigilar a los estudiantes, con la idea obsesiva de que fuman, actividad de la que obtendrá una suerte de placer erótico. De este modo el relato muestra, primero, a la ideología como una voz que habla en la intimidad, a través de la tercera persona

vigilantes de Diamela Eltit, que, a diferencia de la de Kohan, no se focaliza en ellos sino en los vigilados y también la canción de Charly García "Esos raros peinados nuevos", más ambigua, que quizás podría ser leída como lo contrario de una confesión, es decir, una exculpación: "Y si vas a la derecha/y cambiás hacia la izquierda, adelante./ Es mejor que estarse quieto, es mejor que ser un vigilante." 
focalizada claustrofóbicamente que la interioriza, para luego develar el mecanismo por el cual los sujetos subalternos -deseo, compulsión, empoderamiento y satisfacción mediante- se hacen parte del terrorismo de estado y colaboran con él.

\section{"Yo la peor del mundo"}

La vida doble de Arturo Fontaine es la historia de la integrante del grupo revolucionario inverosímilmente llamado Hacha Roja (ficcionalización del Movimiento de Izquierda Revolucionario, MIR), Lorena o Irene, quien es capturada por la policía secreta de Pinochet en un asalto a una casa de cambio, torturada y luego liberada, para ser detenida una segunda vez, ocasión en la cual traiciona a sus compañeros al ser amenazada su hija pequeña. La mujer se convierte entonces en agente de la Central, ficcionalización de la CNI (la Central Nacional de Informaciones, sucesora de la DINA), donde interroga a los detenidos con el seudónimo de la Cubanita y entrega información que permite capturar a varios de sus "hermanos". Además, se involucra sentimentalmente con uno de los jefes de la policía secreta, el Flaco, con el cual participa en orgías y consume drogas. Tras una operación sangrienta en la que muere el líder de los rebeldes, el Hueso, gracias a la información entregada por Irene, ésta pide protección en la embajada de Suecia y viaja a ese país con su hija. Cuando ésta crece, vuelve a Chile, y la mujer queda sola y luego enferma de cáncer. En estado terminal, le relata su historia a un escritor que le ha pagado por ello.

El modo narrativo ya no es la tercera persona en un principio distante que casi de inmediato se internaliza de Ciencias morales, sino un relato homoautodiegético sin fisuras, que se enmarca en una entrevista. Podemos percibir aquí una actualización de la confesión en un género periodístico, en el que, no obstante, se distinguen las figuras básicas de ésta: la pecadora y el confesor, que es quien domina la situación. Así, en las líneas iniciales, una pregunta de la narradora da cuenta de esta relación de poder: “Podría yo decirte la verdad? Ésa es una pregunta para ti. ¿Me vas a creer o no? A eso solo respondes tú. Lo que yo sí puedo hacer es hablar. Y allá tú si me crees" $(11)^{9}$.

Al igual que en la novela de Kohan, en la de Fontaine sobrevuela una pregunta por el origen de la colaboración. Para responderla se da cuenta de los febles principios revolucionarios de Lorena y de sus compañeros de militancia, pero sobre todo de los efectos demoledores de la tortura:

Los días no se distinguen de las noches y todo transcurre en una atmósfera gaseosa atravesada de pavores. Si hubiera cómo contar lo que te ocurre ahí adentro, ¿Qué eres?, ¿un animal enajenado por el horror?, ¿dónde estás?, ¿qué esperas?

9 El último de los tres epígrafes de la novela, de Regis Debray, expresa la situación desmedrada de la mujer: "[el examen de conciencia es un juego crepuscular donde el escrupuloso pierde todas las veces]". 
Desde que te ponen la venda sales de ti y entras en una pesadilla sin formas definidas... Un grito para recoger todo eso y una lengua para ahorcarme $(15)^{10}$.

También se ahonda en el sufrimiento corporal y en la fragilidad e indefensión que este genera: "El dolor me va forjando aunque todavía no lo sé. Siempre lo hace. La llama que ablanda y moldea los metales. Es cuestión de alcanzar la temperatura apropiada a cada uno... Tú no imaginas lo que es eso. No puedes. Eres una cucaracha a la que cualquiera tiene derecho a reventar de un pisotón" $(16)^{11}$. Todo esto explica el "pacto faústico" (155) que hace Lorena y tiene como consecuencia la máxima degradación, expresada con lenguaje bíblico: "yo bebo el cáliz de mi propia abyección, es dulce y amargo mi cáliz como un vicio" (258).

El empleo de un imaginario religioso hace pensar en la cercanía con la confesión, pero más significativo, teniendo en mente las ideas de Foucault sobre este sacramento, es que el personaje que construye Fontaine está obsesionado por su interioridad: "La sordera es un ruido constante, un zumbido interior que detiene las voces y sonidos que te llegan obligándote a oír siempre lo que viene de adentro tuyo" (12). Así, en "El sujeto y el poder" Foucault plantea que el cristianismo da inicio a un nuevo tipo de poder, el pastoral, que busca la salvación del individuo en la otra vida de manera particularizada, lo cual se vincula con "la producción de verdad, la verdad del individuo en sí mismo"12. En tanto, en La voluntad de saber agrega que "la confesión se convirtió, en Occidente, en una de las técnicas más altamente valoradas para producir lo verdadero. Desde entonces hemos llegado a ser una sociedad singularmente confesante" (74), "[e]l hombre... ha llegado a ser un animal de confesión (75). Lo anterior tiene como efecto que la "obligación de confesar nos llega ahora desde tantos puntos diferentes, está ya tan profundamente incorporada a nosotros que no la percibimos más como efecto de un poder que nos constriñe; al contrario, nos parece que la verdad, en lo más secreto de nosotros mismos, sólo 'pide’ salir a la luz" (76). Es ésta una trampa y un engaño, que invierte el sentido de las cosas:

Es preciso que uno mismo haya caído en la celada de esta astucia interna de la confesión... también es necesario haberse construido una representación harto invertida del poder para llegar a creer que nos hablan de libertad todas esas voces que en nuestra civilización, desde hace tanto tiempo, repiten la formidable conminación de decir lo que uno es, lo que ha hecho, lo que recuerda y lo que ha olvidado, lo que esconde y lo que se esconde, lo que uno no piensa y lo que

10 Este último texto de Artaud, en cursivas, aunque sin indicación del autor.

11 "Y vuelven los espasmos, saltas, te revuelcas sin control, eres una muñeca enloquecida, que se daña a sí misma. Es una explosión inaguantable que viene desde adentro y que tu propio organismo retiene convulsionado, un choque de olas contrapuestas en las que tu cuerpo ya no es más tuyo, se te escapa desgajándose, y sin embargo sigues sufriendo tú con intensidad inacabable... El dolor se mueve. Tu propio dolor te enloquece dislocándote. Mi dolor que es mi dolor. Nadie puede entrar adentro de él” (18-19).

12 En: http://www.campogrupal.com/poder.html. Sin número de página. 
piensa no pensar. Inmensa obra a la cual Occidente sometió a generaciones a fin de producir... la sujeción de los hombres; quiero decir: su constitución como 'sujetos', en los dos sentidos de la palabra (76-77).

De este modo en La vida doble, es la interiorización obsesiva, unida a la visión de sí misma como abyecta y culpable, la que constituye al personaje como un yo: "Nada que pueda pensar me saca de aquí. Esta obstinación es una manera de subsistir, de seguir siendo yo gracias a mi culpa" (18). Así entendida, la novela es una gran confesión en que la narradora intenta dar cuenta de su dolor, explicar sus razones, entender lo que le ocurrió y asumir sus culpas, como parte de su construcción identitaria. A través de la entrevista, el escritor todo el tiempo apelado, pero siempre ausente, repite la escena del interrogatorio y la tortura, escena traumática que se vuelve a representar, en que Irene vuelve a hacer presente una y otra vez su posición como víctima de la dictadura.

En el contexto de este artículo uno podría preguntarse por qué no es el Flaco quien rinde cuentas de su actuación. Pero el torturador solo aparece como el amo ausente, al cual no es posible exigirle nada, mucho menos una confesión: "Entonces el amo dominará a la hermana Irene y yo me iré desgastando y llegaré a ser una cosa para él, su esclava... El amo logrará ir doblegándome como si llegase a ser un animalito suyo. El rostro que no puedes ver empieza a ser un todopoderoso, mi aterrador deus absconditus, mi dios escondido" (15-16) ${ }^{13}$.

En resumen, en La vida doble los modos de la entrevista y la primera persona ${ }^{14}$ reproducen en la ficción la escena de la tortura y del interrogatorio así como la relación de poder de la confesión, a través de un escritor que obliga a recordar, a traer al presente y a narrar, a la protagonista estas escenas traumáticas. El torturador y el escritor, en cambio, se mantienen en la sombra, al resguardo del poder, en este sistema de la administración de las culpas que estoy tratando de identificar en la ficción como sintomático de la posdictadura ${ }^{15}$.

13 En la novela hay una delectación en las relaciones de dominación logradas a través de la violencia del tipo amo/ esclavo, especialmente cuando toman un cariz sexual, cercana a una "pornografía del horror" (39): “¿Me creerías si te dijera que más de alguna salía de su calabozo de noche a bailar y a besarse con sus carceleros en alguna discoteca y que eso era parte del horror?" (148). O más adelante: “Ahí dentro, en esa casona transformada en discoteca con hotel, resbalando en la oscuridad movediza con esos ritmos de guitarras agudas y tambores enardecedores, nos fundíamos en un solo mar de alto voltaje y el odio comulgaba con la atracción y el rencor con el olvido y la rabia con la misericordia y el miedo con la risa y la violencia con la ternura y el desamparo con la intimidad" (176).

14 Judith Butler ha reflexionado sobre el uso de la primera persona con respecto a la reacción estadounidense a los atentados del 11 de septiembre: "Necesitamos reforzar el punto de vista en primera persona, e impedir contar historias que indiquen un descentramiento del 'yo' narrativo dentro del dominio político internacional... ¿no hay alguna posibilidad de descentrar la narración en primera persona dentro de un marco global?... si vamos a percibirnos como agentes globales actuando en el interior de un campo históricamente establecido... tenemos que salir de la perspectiva narrativa de la unilateralidad... para considerar el modo como nuestra vida está profundamente relacionada con la vida de los otros" (31-32).

15 Parece haber una noción inconsciente de esto es el trasfondo metaliterario de la novela. Así Lorena increpa al escritor: "Tú debes decirle al lector: usted está leyendo una novela, esto es mentira pura... Y sigues contando a partir de ahí y lo haces de tal manera, con tanta magia, que él se te entrega y colabora. Y entonces tú, de nuevo, 


\section{Una vuelta de tuerca}

La última novela a la que me referiré más brevemente es Carne de perra, de Fátima Sime, la cual narra la historia de una joven enfermera, María Rosa, que es detenida por los servicios de seguridad y torturada hasta que se convierte en colaboradora de éstos y termina contaminando al líder de la oposición a Pinochet-suponemos el ex Presidente Eduardo Frei Montalva- con un virus que le causa la muerte luego de ser operado, después de lo que viaja a Suecia para retornar en el Chile de los noventa.

La historia, aunque mucho más breve, tiene varios puntos en común con la de Fontaine: el que la protagonista sea una mujer de izquierda que después de la tortura colabora con la represión, la descripción detallada de las vejaciones a la que es sometida y de la relación amorosa con el torturador, la colaboración que se vuelve más o menos voluntaria, el comportamiento criminal, el exilio nórdico y la soledad del presente. Pero, aparte de algunas diferencias en la trama (por ejemplo, María Rosa no es una partidaria de la lucha armada y su involucramiento político es mucho menor), el relato de Sime se distingue sobre todo por el modo narrativo, mucho más complejo que el de las otras obras comentadas.

Carne de perra se compone de treinta partes sin título, en las que se intercala el pasado de la dictadura, narrado en presente y en tercera persona, con el Chile de la vuelta a la democracia, relatado en pasado y en primera. Por una parte: "Está desnuda, tirada sobre un piso de baldosas. Tiene los ojos vendados y las manos atadas a la espalda" (7). Por la otra: "Esa noche en la Posta Central era un caos. En la urgencia del primer piso, con los boxes llenos, se atendía en los pasillos, en cualquier espacio... Yo bajaba en el ascensor desde el sexto piso... estaba buscando al médico jefe de turno" (11). Es decir, el modo narrativo distancia a la protagonista de la tortura, la colaboración y el asesinato, aunque convierte lo ocurrido en los setenta en una especie de presente eterno, y aleja el tiempo más cercano de los noventa, aunque lo acerca a través de la primera persona. A lo anterior se suman los numerosos diálogos, sobre todo los que sostiene la protagonista con su torturador, como por ejemplo, el inicial (que más adelante se repetirá):

¿Por qué nos detenemos?, dice ella. ¿No íbamos a ir al cine? ¡Muñeca! La tarde parece de primavera. Caminar por el parque nos va a hacer bien. A mí me gusta ir al cine, me gusta ver películas. Con parsimonia, él apaga el contacto, apaga la radio, apaga el cigarrillo. ¿Tendría que importarme lo que

haces trizas su inocencia. La textura cede, se rompe como un saco roto, lo has traicionado. Era solo una ingeniosa mentira montada sobre la anterior, le dices. Y el lector se marea y nada le parece ni real ni irreal y queda apresado en tus abismos e invenciones, no tiene escapatoria, sólo puede seguir colaborando dócilmente en la obra, la nueva textura, la del nuevo saco, el nuevo manto que enmascara al combatiente... Esto eres si es que eres escritor: un engañador que desengaña para engañar una vez más. Es el poder mon chérie, el ingrato poder que siempre se muestra enmascarado" (129). En el otro extremo, la protagonista parece tener algún grado de conciencia de las relaciones entre confesión (y, en el marco de la tortura, delación) y dominación: "Ésta es una lucha por la información. Estás en un proceso de producción de la verdad, tu cuerpo será la verdad viva” (19). 
a ti te gusta? Hoy no quiero enojarme, ¿sabe? Le tengo una sorpresa, así que ¡ya! ¡Se me baja del auto! Ella obedece (5).

Si bien María Rosa es una mujer marcada, que lleva el estigma de su pasado al igual que Lorena ${ }^{16}$, la enfermedad terminal de esta última ahora no afecta a la mujer, sino que al torturador, quien pasa de ser todopoderoso a moribundo:

El príncipe que yo buscaba era, ahora, un cuerpo empequeñecido, desnudo, cubierto hasta la cintura por un trozo de sábana vieja. Solo se movía el tórax, una parrilla de huesos perfilados, abriéndose y cerrándose como un fuelle viejo, al ritmo que le imprimía el respirador... Los dientes amarillos por la nicotina, manchados también de sangre, simulaban encías desdentadas. Con los párpados entreabiertos y las pupilas dilatas por los sedantes que le permitían tolerar el respirador, sus ojos eran un par de huecos oscuros. Parecía una calavera (35).

El hombre sufriente le pide a María Rosa que lo mate, pero ella, en un primer momento, en lo que da cuenta de la recuperación de su capacidad de agencia, decide vengarse y torturarlo y comienza a llevarlo a cabo. Sin embargo, muy pronto, termina aplicándole a su antiguo torturador la eutanasia que él desea, en una forma de agencia más evolucionada, ya que le permite salir del círculo de la violencia propia del vínculo amo/esclavo.

Pienso que en Carne de perra el modo narrativo permite elaborar una salida para el personaje femenino traumatizado por la tortura, como alternativa a la confesión en primera persona que construye un personaje subjetivizado, culpabilizado y destinado a la muerte que se representa en La vida doble. Si bien también en la novela de Sime se trata de un sujeto dañado, la distancia que se opera sobre el pasado a través de la tercera persona y la importancia del diálogo directo, en lugar de la repetición de la escena del interrogatorio en el presente, hacen posibles la vuelta de tuerca, la huida de la lógica de la violencia ejercida contra el débil, e incluso de la posibilidad, rápidamente desechada, de su inversión.

En Carne de perra el foco ya no apunta de manera cerrada a la mujer violentada y luego cooptada; se ha producido la salida de la celda de tortura y del confesionario y las culpas de la colaboración cesan de cargarse en exclusiva en el personaje subalterno. Esto abre la posibilidad de pensar en las condiciones sociales y políticas que hicieron factibles están acciones, más allá de las causalidades personales. En sus reflexiones sobre la reacción estadounidense frente al bombardeo de las torres gemelas, Judith Butler se ha referido a la necesidad de producir este cambio de perspectiva:

Tanto el discurso del individualismo como el del moralismo... presuponen que el individuo es el primer eslabón de una cadena causal de la que depende

16 Ambas tienen el estatuto que tenía el penitente en el cristianismo inicial, según la explicación que da Foucault de este (Tecnologías del yo 82-83). 
el sentido de los hechos. Pero tomar los actos de un individuo como punto de partida de un razonamiento moral significa precisamente clausurar la posibilidad de preguntar qué tipo de mundo les "da forma" a estos sujetos.

$\ldots$

Nuestros actos no son autosuficientes sino condicionados, actuaron sobre nosotros al mismo tiempo que actuamos, y nuestra "responsabilidad" descansa sobre la articulación de ambas cosas (40-41).

Otras dos importantes novelas del periodo -El desierto (2005) de Carlos Franz y Nocturno de Chile (2000) de Roberto Bolaño- se centran en personajes que hacen su confesión. La primera está dentro del paradigma, pues quien se confiesa es nuevamente una mujer, una jueza que se ha involucrado con el militar a cargo de la represión a inicios del golpe militar en un pueblito del norte de Chile. En cambio, la segunda escapa por completo del prototipo, pues en el relato se obliga, en una noche de fiebre y delirio, a confesarse a una figura que si bien no estuvo vinculada directamente con las violaciones a los derechos humanos, sí fue ideológicamente significativa en la dictadura: el sacerdote del Opus Dei y crítico literario Sebastián Urrutia Lacroix, quien, como se sabe, es una ficcionalización de José Miguel Ibáñez Langlois, conocido como el cura Valente, juez literario del importante diario El Mercurio. Con los mismos medios que centran la mirada en la culpa de las mujeres subalternas -la narración en primera persona, el enclaustramiento, la enfermedad y la confesión-, Bolaño pone el foco en un personaje que sí fue parte del poder dictatorial.

La primera persona, la focalización cerrada, el ver el mundo cada uno desde el vidrio de su pecera, es la perspectiva desde la cual se suele relatar la culpa en las novelas recientes, centrada en la subjetividad de personajes subalternos. Pero en Carne de perra Fátima Sime abre la reja de la interioridad enclaustrada, rompiendo el empecinamiento en la voz única, en la monofonía y en el diálogo interior cerrado, saliéndose de la estructura de poder de la confesión para proponer posibilidades diversas a la violencia y la muerte. Por su parte, en Nocturno de Chile, Roberto Bolaño dispone las mismas formalidades para un personaje cercano al poder, a quien obliga a representarse sus culpas. Por estos medios ambos autores logran desordenar el régimen inicial de administración de las culpas de la posdictadura, que carga a los menos empoderados con las responsabilidades de muchos.

\section{Referencias}

Althusser, Louis. Ideología y aparatos ideológicos del Estado. Freud y Lacan. Buenos Aires: Nueva Visión, 2005. Medio impreso.

Arce, Luz. El infierno. Santiago: Planeta, 1993. Medio impreso. 
Arendt, Hannah. Eichmann en Jerusalén: un estudio sobre la banalidad del mal. Barcelona: Lumen, 2000. Medio impreso.

Barthes, Roland. Mitologías. México: Siglo XXI, 1997. Medio impreso.

Bolaño, Roberto. Nocturno de Chile. Barcelona: Anagrama, 2000. Medio impreso.

Butler, Judith. Vida precaria. El poder del duelo y la violencia. Buenos Aires: Paidós, 2009. Medio impreso.

Callejas, Mariana. Siembra vientos. Santiago: Cesoc, 1995. Medio impreso.

Kohan, Martín. Ciencias morales. Barcelona: Anagrama, 2007. Medio impreso.

Franz, Carlos. El desierto. Santiago: Sudamericana, 2005. Medio impreso.

Fontaine, Arturo. La vida doble. Buenos Aires: Tusquets, 2010. Medio impreso.

Foucault, Michel. Tecnologías del yo y otros textos afines. Barcelona: Paidós Ibérica 1990. Medio impreso.

---. Historia de la sexualidad. 1. La voluntad de saber. México D.F.: Siglo XXI, 1993. Medio impreso.

---. "El sujeto y el poder". En Campo Grupal: http://www.campogrupal.com/poder. html. Consultado el 12 de febrero de 2014. Sitio web.

Guzmán, Nancy. Confesiones de un torturador. Santiago: Planeta, 2000. Medio impreso.

Merino, Alejandra. Mi verdad: más allá del horror, yo acuso. Santiago: ATG, 1993. Medio impreso.

Silva Encina, Gisela. Miguel Krassnoff. Prisionero por servir a Chile. Santiago: Maye, 2007. Medio impreso.

Sime, Fátima. Carne de perra. Santiago: LOM, 2009. Medio impreso.

Suárez, Úrsula. Relación autobiográfica. Santiago: Biblioteca Nacional, Universidad de Concepción, Seminario de Filología Hispánica y Academia Chilena de la Historia, 1984. Medio impreso.

Recibido: 03 marzo 2014 Aceptado: 08 septiembre 2014 